\title{
A Minimal-Order Observer Based Control Method for PV Generator to Reduce Frequency Deviations of Power System
}

\author{
Tomonobu Senjyu ${ }^{1}$, Manoj Datta ${ }^{1}$, Atsushi Yona ${ }^{1}$, Toshihisa Funabashi ${ }^{2}$, and Chul-Hwan Kim $^{3}$ \\ ${ }^{1}$ Department of Electrical and Electronics Engineering \\ University of the Ryukyus, 1 senbaru Nishihara-cho Nakagami, Okinawa 903-0213, Japan \\ Phone: +81988958686, e-mail: b985542@tec.u-ryukyu.ac.jp, k068472@eve.u-ryukyu.ac.jp \\ ${ }^{2}$ Meidensha Corporation, ThinkPark Tower, 2-1-1 Osaki, \\ Shinagawa-ku, Tokyo 141-6029, Japan \\ Phone: +810364207208, E-mail: funabashi-t@mb.meidensha.co.jp \\ ${ }^{3}$ School of Electrical and Computer Engineering, \\ Sungkyunkwan University, Suwon City 440-746, Korea \\ E-mail: chkimskku@yahoo.com
}

\begin{abstract}
In this paper, a minimal-order observer based control method is proposed for small power utility connected PV systems. In the proposed method, the PV power is controlled according to load variation to minimize the frequency deviation. Load power and diesel power is estimated by a minimal order observer successfully. From the estimated load power, load variation index is calculated. A second-order low-pass filter is used to produce PV base power from available maximum PV power. Then, PV base power is added with the load variation index to generate the command PV power. The proposed method is compared with the method where Maximum Power Point Tracking (MPPT) control is used to produce the command PV power. From simulation results, it has been found that the proposed method is effective to reduce the frequency deviation of the utility and also delivers PV power near maximum PV power.
\end{abstract}

\section{Key words}

Frequency deviation, Minimal-order observer, Maximum Power Point Tracking, load variation, PV base power.

\section{Introduction}

The demand of renewable energy has been increased significantly because of the shortage of fossil fuel and the global green house effect. Among various renewable energy systems, photovoltaic power generation systems (PV systems) are expected to play a promising role as a clean power electricity source in meeting future electricity demands. However, PV power fluctuates depending on weather conditions, season, and geographic location and may cause problems like voltage fluctuation and large frequency deviation in electric power system operation [1], [2]. To date, It has not been necessary for small PV generators to provide frequency regulation services to the power system. In the future, with an increasing penetration of PV generation, their impact upon the overall control of the power system will become significant [3]. This will lead a situation where the PV generators will be required to share some of the duties, such as load frequency control. Therefore, for the penetration of large PV system's output power in the utility without reduction of the reliability of utility power systems, suitable measures must be applied to the PV systems side.
Several studies have been carried out to minimize the harmful effects of connecting large PV generators with utility. On the PV system side, storage devices like batteries can be used as smoothing devices for a PV system's output. There have been investigations aimed at improving the performance of PV systems equipped with batteries [4]-[7]. However, the capital cost and maintenance cost of batteries is a barrier to the large scale installation of PV systems and used batteries must be disposed of without causing environmental problems [8], [9]. In addition, these methods can not control PV output power considering power utility condition like load variation. Power characteristics of PV ensembles are presented in [10] where monitored data from $100 \mathrm{PV}$ systems were used to study effects of combined power generation of these systems, compared to the characteristics of an individual system. It was claimed that a significant amount of power fluctuations disappeared, however, large amount of short term power fluctuations remained. In addition, when the number of PV power generation systems were decreased, the power fluctuations increased. Smoothing of PV system output by tuning MPPT control is demonstrated in [11]. In this method, when the insolation increases rapidly, the operating MPPT point changes to a new point where the maximum power is not generated with the current insolation. However, the condition of power utilities like frequency deviation is not considered for tuning the MPPT and for limiting the new output voltage. All of these methods tried to smooth the fluctuating PV power. However, none of them give emphasis on controlling the PV power according to load variation and no sharing about load frequency control.

In this paper, a minimal order observer based control method for PV systems to reduce frequency deviations and to control the PV power according to load variation is proposed. This method can capture PV power near maximum PV power available. This method uses minimal order observer to estimate required load power and diesel power. From estimated load power, load variation index is calculated. A second-order low-pass filter is used for producing smooth base PV power. The load variation index is then added with the base PV power to produce final PV power command. The proposed method is compared with MPPT based control 
[12] through simulation and is found effective to reduce frequency deviation of the small power utility as it controls PV power nearly maximum PV power according to the load variation.

The paper is organized as follows: Section II provides concept of small power utility, description of PV power generation system, and brief review of solar module characteristics. Section III describes the minimal order observer. In Section IV, PV output power command generation system is presented. In section $\mathrm{V}$, effectiveness and feasibility of the proposed method is demonstrated by simulation results. Conclusions are drawn in Section VI.

\section{Small Power System}

The concept of small power utility in this paper is shown in Fig. 1. The small power utility consists of the diesel generators and PV systems that generate power to supply the demand. In addition, it is assumed that the small power utility is not connected to large power utility and it is always operated independently like the power system in an isolated island.

The small power system model which consists of diesel generator in detail, PV power generation system, load and diesel power observer, and load is shown in Fig. 2 where $S_{i}$ is the insolation, $P_{i n v}^{*}$ is the command power generated by output power command system, $P_{A}$ is the generated power by $\mathrm{PV}$ power generation system, $P_{d}$ is generated power by diesel generators, $R$ is the speed regulation, $T_{g}$ is the governor time constant, $T_{d}$ is the diesel generator time constant, $P_{L}$ is the load, $M$ is the inertia constant, $D$ is the damping constant, $u$ is the input to the governor, $\Delta f$ is the frequency deviation of small power utility, $\hat{P}_{d}$ is the estimated diesel power, $\hat{P}_{L}$ is the estimated load power.

In Fig. 3, PV power generation system including solar array, inverter and PI controller is shown where $V_{A}$ is the solar array voltage, $I_{A}$ is the solar array current, $\Delta f$ is the frequency deviation, $V_{S}$ is the generated supply voltage by the inverter, $I_{S}$ is generated supply current by the inverter, and $\left|I_{i n v}^{*}-I_{i n v}\right|$ is the error between command current and produced current. The control algorithm for the inverter [13] adopted here is very simple. The inverter output voltages and currents are sensed and transformed from 3-phase to synchronously rotating 2-phase. The command currents are generated dividing the output power command by sensed inverter voltage. Then the error between command inverter current and actual inverter current is processed through a PI controller to generate the PWM pulses. For maximum power extraction, the output power command is generated by maximum power point tracking algorithm. For simple structure and less costly implementation, a Perturbed and Observed (P\&O) [12] algorithm was chosen in the present structure.

Equations given in [14] are used in the development of computer simulations for the solar module. The MATLAB/SIMULINK is used. Fig. 4(a) and (b) shows the simulated ampere-volt and power-volt curves of the solar module for different insolation at constant temperature. Figs. 4(c) and (d) show the simulated ampere-volt and power-volt curves of the solar module for different temperature at constant insolation. From these curves, it is observed that the output characteristics of the solar module are nonlinear and vitally affected by the variation of insolation. However, variation of temperature slightly affects the output characteristics of solar module. Therefore, for the present case study, insolation and temperature variation effects both are taken in to account to model the solar array.

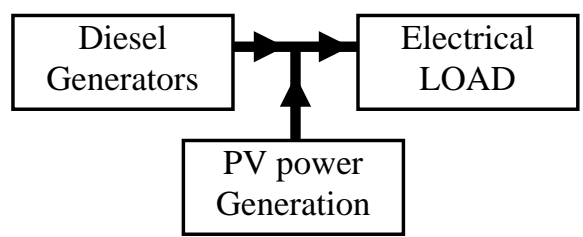

Fig. 1. Concept of small power utility.

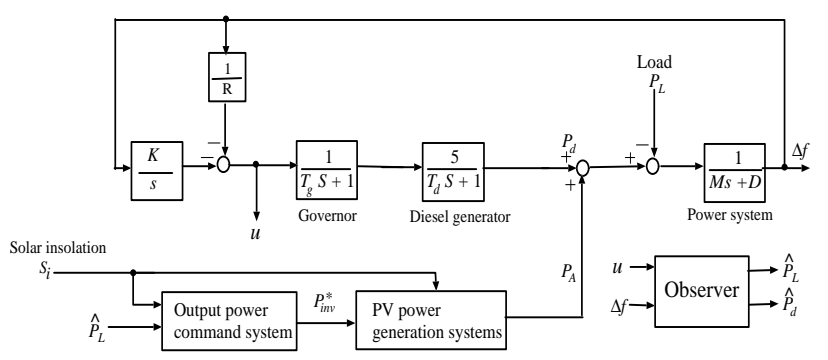

Fig. 2. Small power system model.

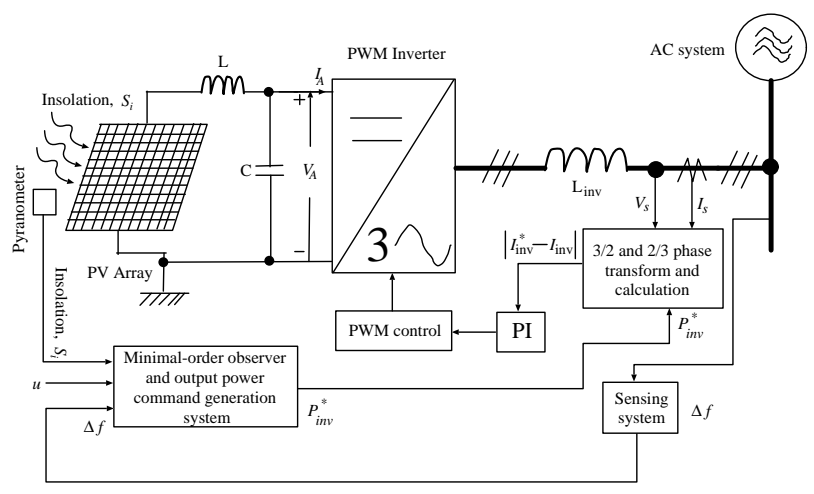

Fig. 3. Photovoltaic power generation system.
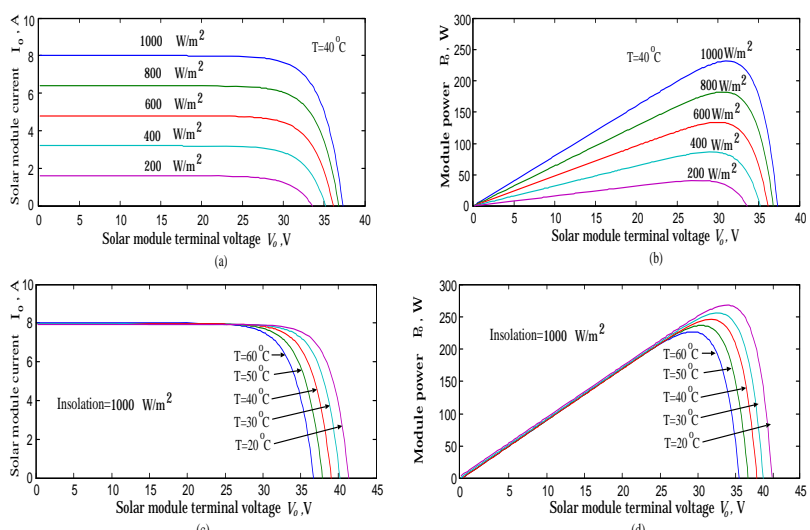

Fig. 4. Solar module characteristic curves. (a) and (c) Current-voltage curves. (b) and (d) Power-voltage curves. (For (a) and (b) temperature is constant; for (c) and (d) insolation is constant). 


\section{Minimal-order Observer Design}

To estimate load power and diesel power, a minimalorder observer is designed. A simple minimal-order observer [15]-[17] is shown in Fig. 5. The state space representation of the plant is obtained by

$$
\begin{aligned}
\dot{x}(t)=A x(t) & +B u(t) \\
y(t) & =C x(t)
\end{aligned}
$$

where $x(t)$ is an $n \times 1$ state vector, $y(t)$ is an $l \times 1$ output vector, $u(t)$ is an $m \times 1$ input vector, $A$ is an $n \times n$ system matrix, $B$ is an $n \times m$ input matrix, and $C$ is an $n \times l$ output matrix.

From [15], the minimal-order state observer can be written as

$$
\begin{gathered}
\dot{\omega}=\hat{A} \omega(t)+K y(t)+\hat{B} u(t) \\
\hat{x}(t)=D \omega(t)+H y(t)
\end{gathered}
$$

where $\omega(t)$ is the $\overline{n-l} \times 1$ state variable of the observer, $D(n \times \overline{n-l}), \quad H(n \times l), \quad \hat{A}(\overline{n-l} \times \overline{n-l}), \quad K(\overline{n-l} \times l)$, and $\hat{B}(\overline{n-l} \times m)$ are design co-efficients in the minimal-order observer, and $\hat{A}=A_{22}-L A_{12}, \quad K=\hat{A} L+A_{21}-L A_{11}$, $\hat{B}=-L B_{1}+B_{2}, D=S^{-1}\left[\frac{0}{I_{n-l}}\right]$, and $H=S^{-1}\left[\frac{I_{l}}{L}\right]$.

The power system model used to design the observer is shown in Fig. 6. From Fig. 6, the co-efficients of the minimal-order state observer can be found as

$$
\begin{aligned}
& \hat{A}=\left[\begin{array}{ccc}
1.75 & 0.2 & -1.95 \\
-9.75 & -10 & 9.75 \\
9 & 0 & -9
\end{array}\right], \quad K=\left[\begin{array}{c}
1.3748 \\
-15.4538 \\
5.265
\end{array}\right], \\
& \hat{B}=\left[\begin{array}{c}
0 \\
10 \\
0
\end{array}\right], \quad D=\left[\begin{array}{lll}
0 & 0 & 0 \\
1 & 0 & 0 \\
0 & 1 & 0 \\
0 & 0 & 1
\end{array}\right], \quad \text { and } \quad H=\left[\begin{array}{c}
1 \\
-0.195 \\
0.975 \\
-0.9
\end{array}\right] .
\end{aligned}
$$

\section{Output Power Command Generation System}

In order to minimize frequency deviations, output power of PV generator is controlled according to load power. Output power command $P_{i n v}^{*}$ is decided by output power command generation system shown in Fig. 7. After estimating load power $\hat{P}_{L}$, load variation index $\Delta \hat{P}_{L}$ can be found as

$$
\Delta \hat{P}_{L}=\hat{P}_{L}-\frac{1}{T} \int_{t-T}^{t} \hat{P}_{L} d t
$$

Then, $\mathrm{PV}$ base power is obtained by

$$
P_{\text {base }}=P_{\max } \frac{0.78}{10 s+1}
$$

Finally, PV output power command is given by

$$
P_{i n v}^{*}=P_{\text {base }}+\Delta \hat{P}_{L}
$$

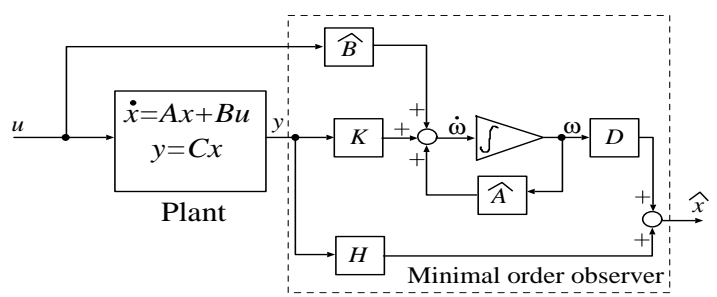

Fig. 5. Structure of minimal-order observer.

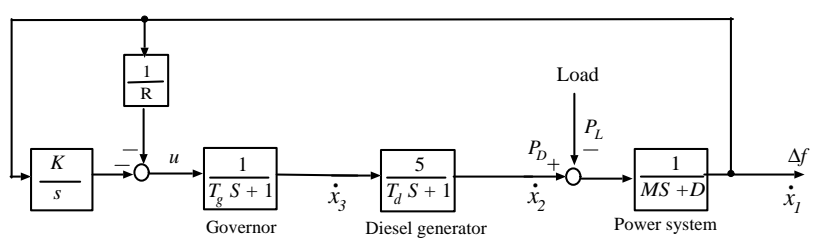

Fig. 6. Power system model used to design minimal-order state observer.

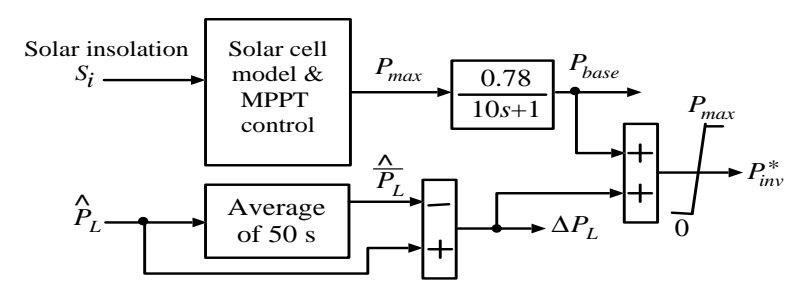

Fig. 7. Output power command generation system.

\section{Simulation Results}

In this paper, the effectiveness of output power control of PV power generation system according to load and frequency deviation reduction of power system using the proposed method is examined by simulation with system model and parameters as mentioned in [14],[18]-[20]. In order to use parameters of real Large PV system given in [19], [20], the rated output power of the PV array is $241 \mathrm{~kW}$. Simulation parameters of power system, PV array, power converter and PI controller are shown in TABLE I. Here, integral time $T$ is $100 \mathrm{~s}$, sampling time $T_{s}$ to obtain discrete value of output power command is $10 \mathrm{~s}$, and sampling time of PI controller is $1 \mathrm{~ms}$. The total simulation time is 30 minutes and the averaging time of insolation and load is 20s.

TABLE I. Simulation Parameters

\begin{tabular}{|l|l|}
\hline \multicolumn{2}{|c|}{ Parameters of small power system } \\
\hline Inertia constant, $M$ & $0.150 \mathrm{puMW} \cdot \mathrm{s} / \mathrm{Hz}$ \\
\hline Damping constant, $D$ & $0.008 \mathrm{puMW} / \mathrm{Hz}$ \\
\hline Governor time constant, $T_{g}$ & $0.10 \mathrm{~s}$ \\
\hline Diesel Time constant, $T_{d}$ & $8.0 \mathrm{~s}$ \\
\hline Speed regulation, $R$ & $2.5 \mathrm{~Hz} / \mathrm{puMW}$ \\
\hline \hline \multicolumn{2}{|c|}{ Parameters of $P V$ array } \\
\hline Rated output power & $241 \mathrm{~kW}$ \\
\hline Open circuit voltage & $588.80 \mathrm{~V}$ \\
\hline Short circuit current & $520.37 \mathrm{~A}$ \\
\hline Number of modules in series & 16 \\
\hline Number of modules in parallel & 65 \\
\hline Total number of cells & 62,400 \\
\hline Cell & Poly -crystalline silicon \\
\hline Standard insolation & $1,000 \mathrm{~W} / \mathrm{m}^{2}$ \\
\hline \multicolumn{2}{|c|}{ Parameters for PI controller } \\
\hline Proportional constant & 0.1 \\
\hline Integral constant & 10 \\
\hline
\end{tabular}


The estimated load power and diesel power by minimalorder observer is shown in Figs. 8(a) and (b) respectively. Here, actual value is shown by dotted line and estimated value is shown by solid line. From Figs. 8 (a) and (b), it can be said that the observer works efficiently as the estimated values are in accordance with actual value.

Fig. 9 shows the comparative simulation results of MPPT control and proposed method. Here, the results obtained by proposed control are shown by solid line and the results obtained by MPPT control are shown by dotted line. Insolation, load variation index, and PV base power is shown in Figs. 9 (a), (b), and (c) respectively. Here, insolation and load varies quickly with time. From Fig. 9 (c), it can be said that the PV base power is smoother than PV maximum power as a second order low-pass filter is used to process the maximum power. Fig. 9 (d) shows the PV power produced by MPPT control and proposed control. From Fig. 9 (d), it is observed that the proposed method produced power near MPPT power but controlled according to the load variation index to minimize the frequency deviations. Fig. 9 (e) shows diesel power needed in the system with proposed control and MPPT control. From Fig. 9 (e), it is seen that diesel power produce with proposed method fluctuates less than the diesel power produced with MPPT control. As diesel generator response is slow, less fluctuating diesel power is good for the system. Fig. 9 (f) shows the frequency deviations where frequency deviations produced by MPPT control are $\pm 0.3 \mathrm{~Hz}$ at maximum time. On the other hand, frequency deviations produced by proposed method are almost zero. Therefore, it can be said that proposed method is effective to reduce frequency deviations of small power utility and also delivers PV power near maximum PV power available.

\section{Conclusion}

This paper presents a minimal-order observer based control method for utility connected large PV systems to reduce frequency deviations. Here, required load power and diesel power of the utility is estimated by the observer. From estimated load power and PV maximum power, command PV power is generated using a secondorder low pass filter. From the simulation results, it has been found that the proposed method is effective to reduce frequency deviations significantly in comparison with MPPT control. Also, the proposed method produces PV power near maximum PV power. The current practice to reduce frequency deviation is smoothing of PV output power fluctuations. However, proposed method shows a new and simple control of PV power to reduce frequency deviations without smoothing PV output power fluctuations. Therefore, it can be said that proposed method can be used to share some of the duties like load frequency control by PV generator.

\section{References}

[1] S. Yanagawa, T. Kato, K. Wu, A. Tabata, and Y. Suzuoki, "Evaluation of LFC capacity for output fluctuation of photovoltaic generation systems based on multi-point observation of insolation," in Proc. IEEE Power Engineering Society Summer Meeting, 2001, pp. 1652-1657.

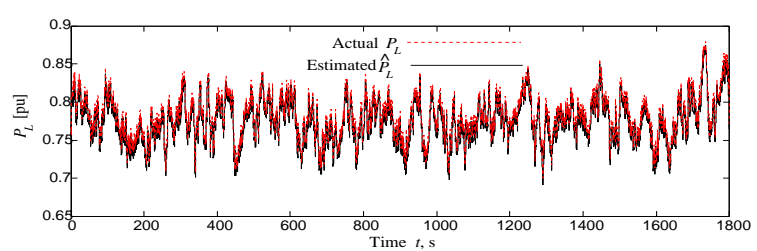

(a) Estimated load power $\hat{P}_{L}$

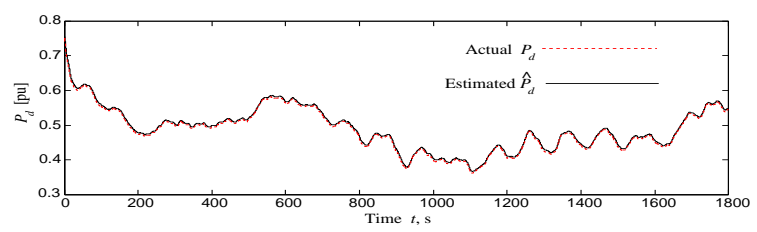

(b) Estimated Diesel power $\hat{P}_{d}$

Fig. 8. Performances of the minimal-order observer.

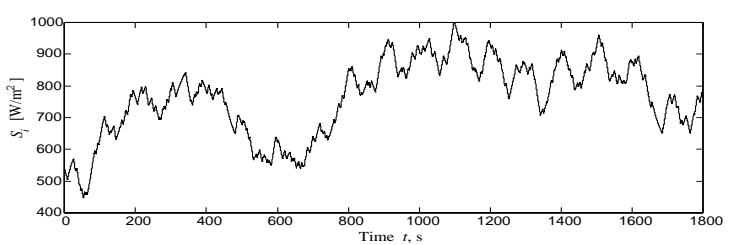

(a) Insolation

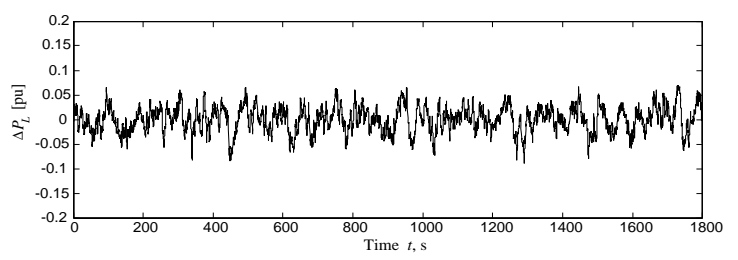

(b) Load variation index

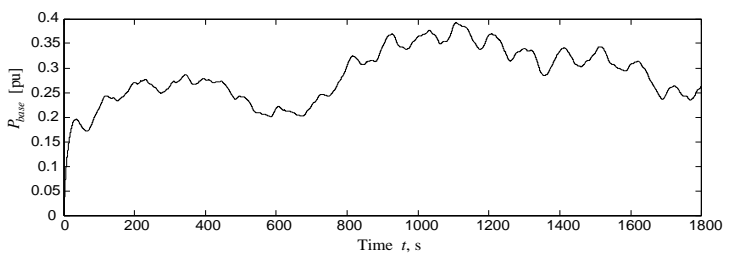

(c) PV base power

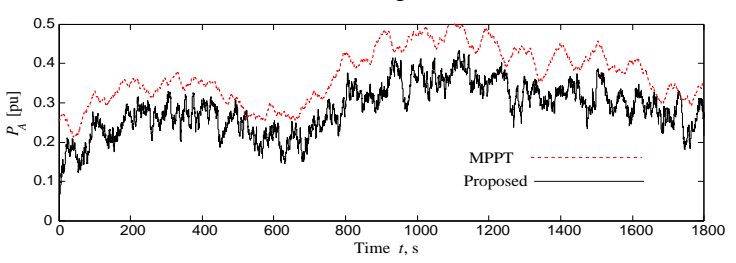

(d) PV power supplied to power system

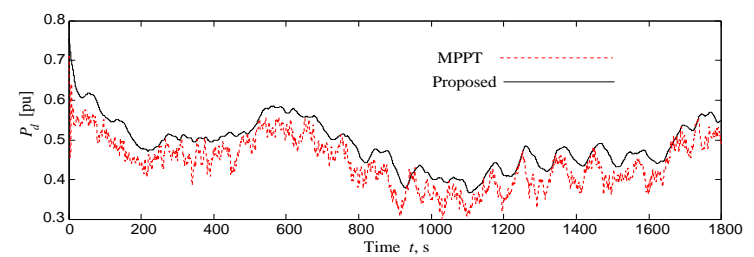

(e) Diesel power

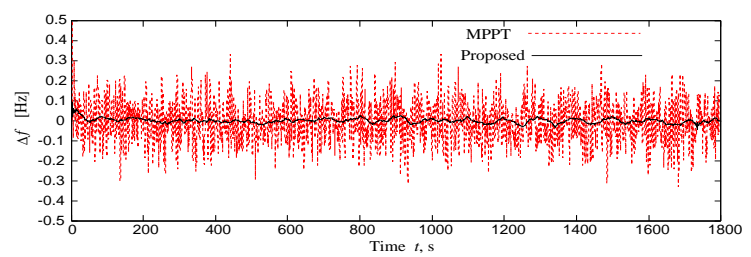

(f) Frequency deviations

Fig. 9. Comparative simulation results of the proposed control and MPPT control. 
[2] A. Woyte, V.V. Thong, R. Belmans, and J. Nijs, "Voltage fluctuations on distribution level introduced by photovoltaic systems," IEEE Trans. Energy Convers., vol. 21, no. 1, pp. 202-209, March 2006.

[3] Y.T. Tan, D.S. Kirschen, and N. Jenkins, “A model of PV generation suitable for stability analysis," IEEE Trans. Energy Convers., vol. 19, no. 4, pp. 748-755, Dec 2004.

[4] T. Kinjo, T. Senjyu, N. Urasaki, and H. Fujita, "Output levelling of renewable energy by electric double layer capacitor applied for energy storage system," IEEE Trans. Energy Convers., vol. 21, no.1, pp. 221- 227, March 2006.

[5] Md. H. Rahman and S. Yamashiro, "Novel distributed power generating system of PV-ECaSS using solar energy estimation," IEEE Trans. Energy Convers., vol. 22, no.2, pp. 358-367, June 2007.

[6] J. P. Barton and D. G. Infield, “A probabilistic method for calculating the usefulness of a store with finite energy capacity for smoothing electricity generation from wind and solar power," Journal of Power Sources., vol. 162, pp. 943948, 2006.

[7] R. Wanger, "Large lead/acid batteries for frequency regulation, load levelling and solar power applications," Journal of Power Sources, vo. 67, pp. 163-172, 1997.

[8] H. Sugihara, S. Nishikawa, and Y. Kimura, "Observation of the hybrid system using photovoltaic and sodium-sulphur battery,"in Proc. JSES/JWEA Joint Conference, 2001, pp. 13-16.

[9] H. Miyauchi, K. Eguchi, and H. Hayashi, "SEMS to power quality improvement," in Proc. IEEJ Conference of Power and Energy Society, 2002, pp. 110-115.

[10] E. Wiemken, H.G. Beyer, W. Heydenreich, and K. Kiefer, "Power characteristics of PV ensembles: experiences from the combined power production of 100 grid connected PV systems distributed over the area of Germany," Solar Energy, vol. 70, no. 6, pp. 513-518, 2001.
[11]N. Ina, S. Yanagawa, T. Kato, and Y. Suzuoki, “Smoothing of PV system output by tuning MPPT control," Willey Electrical Engineering in Japan, vol. 152, no. 2, pp. 10-17, 2005.

[12] N. Femia, G. Petrone, G. Spagnuolo, and M. Vitelli, "Optimization of perturb and observe maximum power point tracking method,” IEEE Trans. Power Electron., vol. 20, no. 4, pp. 963-973, July 2006

[13] K. Kobayashi, I. Tanako, and Y. Sawada, “A study of a two stage maximum power point tracking control of a photovoltaic system under partially shaded insolation conditions," Solar Energy Materials \& Solar Cells, vol. 90, pp. 2975-2988, 2006.

[14] C. Hua, J. Lin, and C. Shen, "Implementation of a DSP controlled photovoltaic system with peak power tracking," IEEE Trans. Ind. Electron., vol. 45, no. 1, pp. 99-107, Feb. 1998.

[15] S. Goto, and M. Nakamura, "Multidimensional feedforward compensator for industrial system through pole assignment regulator and observer," IEEE Trans. Ind. Electron., vol. 53, no. 3, pp. 886-894, July 2006.

[16] D. G. Luenburger, "An introduction to observer," IEEE Trans. Autom. Control, vol. AC-16, no. 6, pp. 596-602, Dec. 1971.

[17] T. Mita, "On the estimating errors and the structures of the identity observers and minimal order observers

[18] T. Senjyu, T. Kaneko, A. Yona, N. Urasaki, T. Funabashi, F. Yamada, and S. Sugimoto, "Output power control for large wind power penetration in small power system," in Proc. IEEE PES General Meeting, sessionwindpower, CD-ROM, 2007.

[19] [Online]. Available: http://www.powerlight.com/ success/ pdf/ LVVWDRonzone Reservoir.pdf.

[20] [Online]. Available: http://www.xantrex.com/web/ id/ 214/ $\mathrm{p} / 1840 / \mathrm{pt} / 23 /$ product.asp. 